\title{
Work-life advantages of becoming a salaried physician may be oversold
}

\author{
— Cite as: CMAJ 2019 January 28;191:E113-4. doi: 10.1503/cmaj.109-5699
}

Posted on cmajnews.com on Jan. 9, 2019.

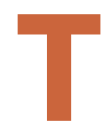

he way doctors want to practise medicine in Canada is changing. The new generation of physicians is less interested in independent practice as they seek better work-life balance and financial security. More than half of resident doctors in Canada would give up some clinical autonomy for a salaried position that included health benefits, pensions and vacation time, according to a recent survey by Resident Doctors of Canada. A salary model was the most appealing option to $41 \%$ of survey participants.

Dr. Tehmina Ahmad, a member of the survey team, says younger physicians are less inclined to take on the entrepreneurial risk of their own practice because they are heavily burdened by student debt on average, more than $\$ 127000$ at graduation. "They are looking for more income security and more predictable hours," she says.

Better work-life balance is also important to young doctors, for whom burnout is a major issue, says Ahmad. In the survey of residents, $52 \%$ indicated they were suffering from burnout.

But if the goal is to avoid burnout, moving to an employee model may not be the best option, says Dr. Dike Drummond, who provides career and life coaching for doctors through his consultancy The Happy MD. In the United States, there has been a radical change in how doctors practise over the past five years, with many independent primary care practices being bought out by local hospitals because of the burdens of dealing with the business side of medicine. In 2016, for the first time, less than half of US physicians owned their own practices.

That shift has coincided with an increase in burnout among doctors. A

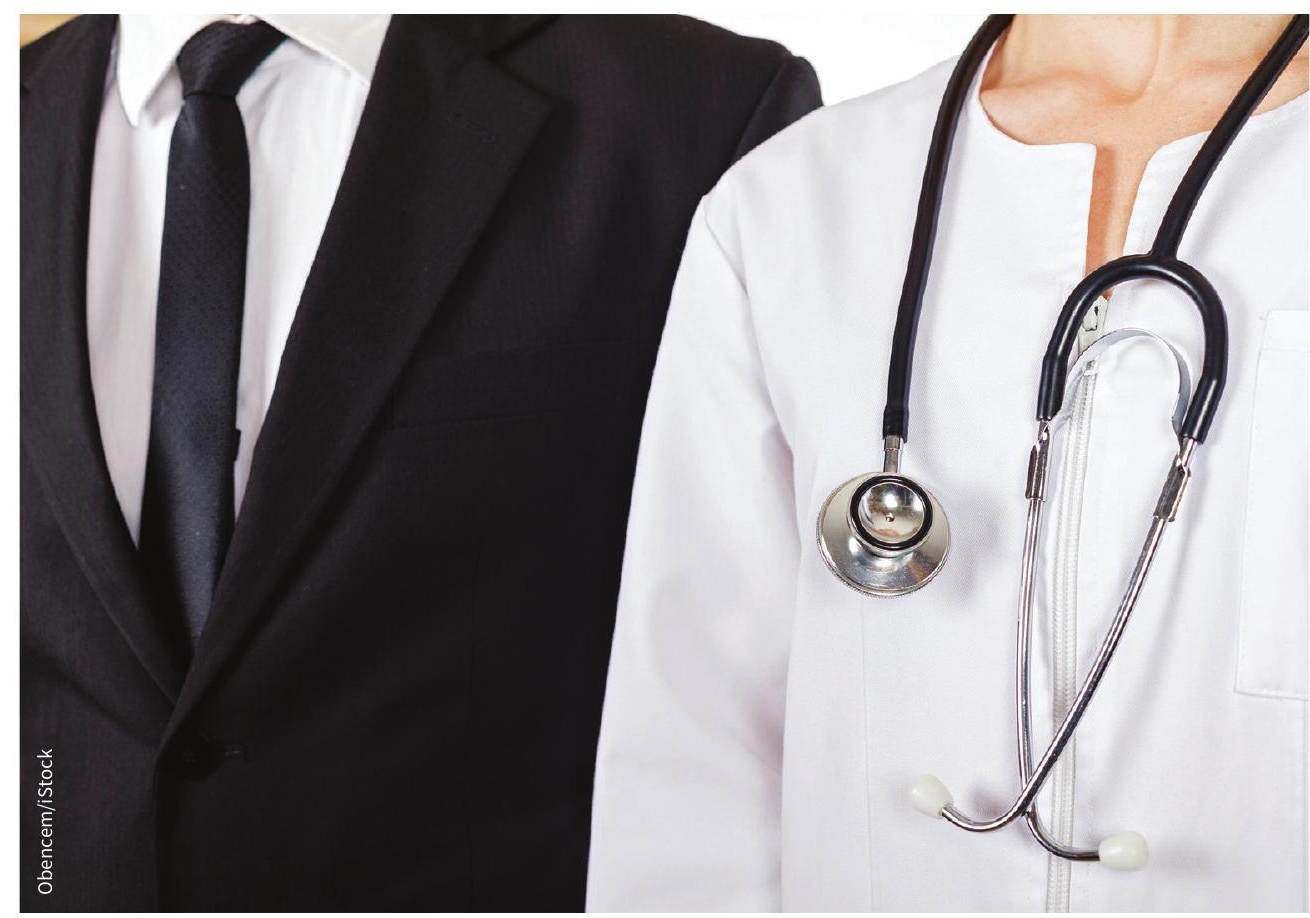

The relationship between salaried doctors and non-physician managers can be a bumpy one.

study by the Mayo Clinic found that in 2011, 45\% of doctors reported suffering from burnout, which rose to 54\% in 2014.

Drummond thinks that is driven in part by the loss of autonomy when a doctor becomes an employee. "We are trained to be the boss, not the middle layer of a huge bureaucracy," he says. "We never learn the skills to navigate bureaucracy or manage our boss. Reporting to a manager who is not a doctor or nurse can be infuriating."

Still, the trend toward more employee-doctors is likely to continue, says Drummond, as younger doctors balk at the number of hours older generations considered part of normal practice. New doctors may be more comfortable being employees, but they will need to develop the skills to work effectively within a bureaucratic organization to manage burnout, something that is still new to the medical profession. "Burnout it not a problem; it's a dilemma," says Drummond. "There's no solution; it needs to be managed with a strategy."

In Canada, alternative payment models are a mixed bag, and may include salaried positions within hospitals or clinics, contract work, fixed payments based on the number of patients assigned to a practice, or some mixture of payment types. The proportion of payments outside the traditional fee-for-service model is higher today than in the 1990s, says Geoff Ballinger, manager of physician information at the Canadian Institute for Health Information; it peaked at around 30\% in 2008-09 and has since stabilized. The proportion of 
alternative payments is higher for younger doctors and women, he says.

What kind of payment model doctors prefer can change throughout their career, says Ballinger. "Younger doctors, with different family obligations, might have a preference for not working 60 - to 80-hour weeks," he says. "Later their situation might change, and they may move towards more fee-for-service work."

A similar trend is happening in the United Kingdom, says Dr. Sandesh Gulhane, co-chair of the British Medical Association's general practitioners' trainee subcommittee. Although the independent contractor model for general practitioners is central to how the National Health Service works, doctors who have recently completed their training are not as keen to take on partnerships in private practices, preferring to do sessional or locum work at the start of their careers.

The financial risk of taking on a partnership is a major part of that reticence, says Gulhane, but so is the lack of training in the business side of medicine. "When we are being trained, we are trained to be salaried, not to be a partner - how to deal with finance, employees, health boards or even a hole in the car park," he says. "When you first qualify, it can be quite frightening."

If business courses were offered as part of their training, more young doctors might be willing to take up partnerships. Indeed, after about five years of practising, many doctors become independent contractors. "Trainees don't understand what it means to be an independent contractor and the benefits that come with it, like flexibility and autonomy," says Gulhane. "If we don't expose people to it, they can never have a balanced view."

Brian Owens, St. Stephen, NB 